\title{
El Porvenir vs. El Católico Masonismo y ultramontanismo periodístico en confrontación (1892)
}

Roberto Armando Valdés Valle.

Departamento de Filosofía

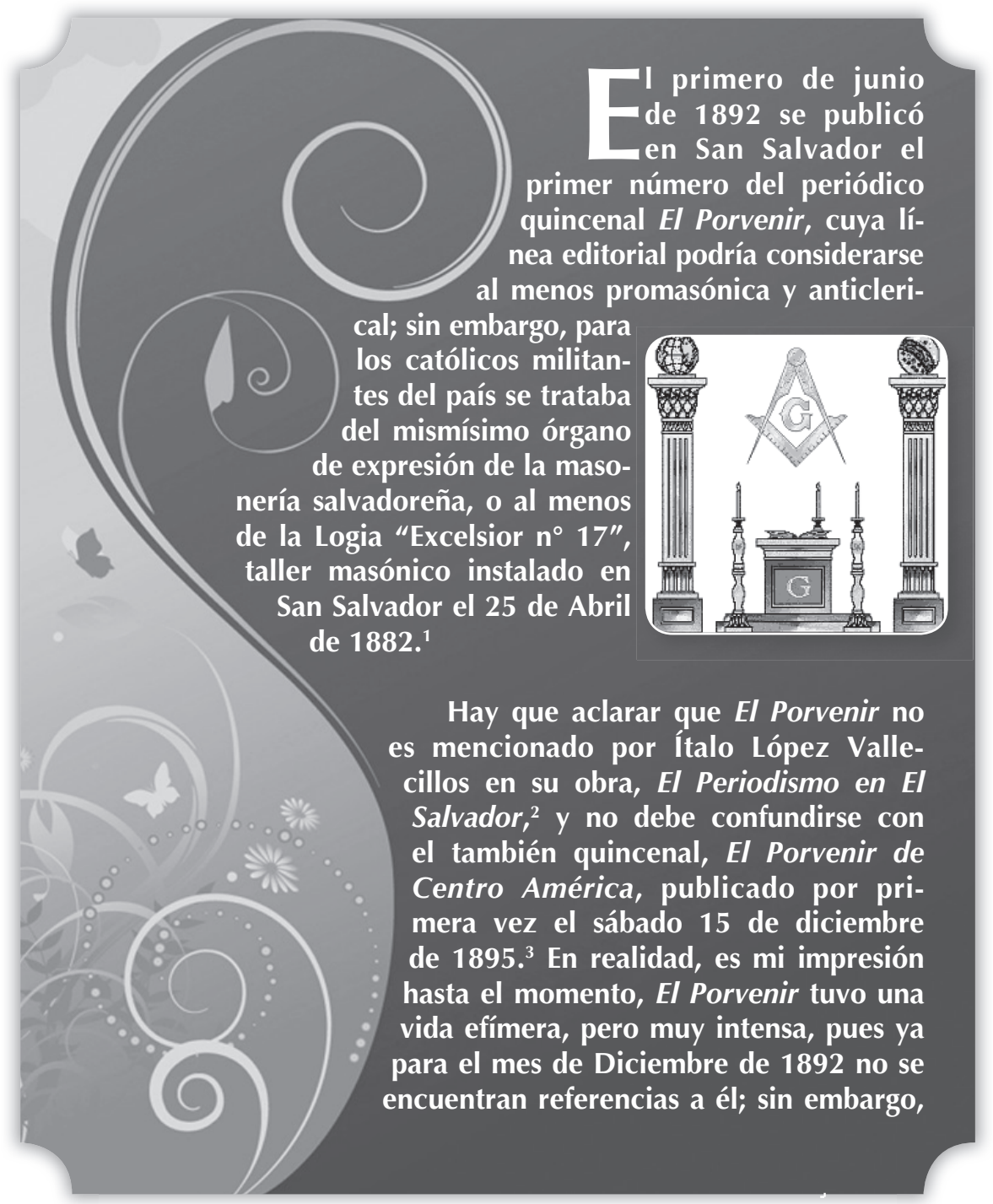


los 7 u 8 números que al parecer se llegaron publicar, dado el carácter promasónico de algunos de sus artículos, los ataques que desplegó tanto en contra de la jerarquía católica salvadoreña como del cuerpo doctrinario-teológico de la religión católica, fueron lo suficientemente agresivos como para generar una fuerte reacción antimasónica entre algunos católicos, quienes Ilegaron a demandar a su editor ante algunos de los tribunales de justicia del país por difamación y falsificación de firmas, logrando que se decretara la captura de su Redactor en Jefe; otros fieles, mucho menos flemáticos, llegaron a plantear públicamente que si se daban las condiciones, estarían dispuestos a llegar a un enfrentamiento a golpes $\mathrm{o}$ a balazos con los editores del periódico pro-masónico. Sin duda un grave prenuncio de lo que se convertirá una constante en el debate político de El Salvador del siglo XX, que con argumentos similares a los expuestos en contra de la masonería y los masones, iniciará una campaña de literal exterminio en contra del comunismo y los comunistas.

En el presente trabajo, pretendo reconstruir el conflicto que generó la aparición y el contenido de algunos de los artículos o comentarios publicados en este medio impreso tan controversial. Para hacer esta reconstrucción, se hará uso del semanario ultramontano, El Católico que se encargó de denunciar $-y$ al mismo tiempo preservar para nosotros- los detalles de este interesante conflicto entre pro-católicos y pro-masones, que, de otra manera se hubiera desvanecido en el tiempo, dado que no se han conservado copias de El Porvenir.

\section{Primeras referencias a El Porvenir. Ataques a Rafael Reyes y a las ideas teológicas defendidas por éste y por el nuevo medio impreso}

La primera noticia sobre la aparición de El Porvenir se encuentra en un comentario publicado en la edición de El Católico del domingo 12 de junio de 1892. En él se denuncia sin tapujos su carácter masónico y trata de identificar al editor en jefe del mismo. ${ }^{4}$ La nota inicia de la siguiente manera: "El Porvenir' es el título de un nuevo periódico quincenal, impreso en la tipografía de 'El Cometa', cuyo primer número circuló el primero del corriente", es decir, el 1 de junio; y a continuación, El Católico se siente en la obligación de revelar el carácter último y los propósitos del mismo, que a juicio de El Católico, se querían mantener en secreto: 
Su programa y sus tendencias [de El Porvenir], su carácter y su estilo están bien marcados, y son por consiguiente bien conocidos ya de cuantos hayan leído su primera plana. Lo que no está bien marcado, lo que parece ocultarse cuidadosamente, es la procedencia y el principal ó soberano director de "El Porvenir". Y como la opinión pública necesita saberlo para apreciar en su justo valor al nuevo huésped, repetiremos lo que personas fidedignas aseguran acerca de esto. "El Porvenir" es el órgano de la masonería salvadoreña, ó Logia Excélsior, que, lo mismo que la masonería universal, lo mismo que todas las logias del mundo, tiene el fin principal de combatir el catolicismo por todos los medios posibles. "El Porvenir" tiene por soberano director al S.: G.: I.: Rafael Reyes n.: 33, y Profesor de Derecho Natural en la Universidad Nacional. Siendo dicho quincenal órgano de la masonería, nadie extraña que todo él se ocupe de combatir y de calumniar, de insultar y de ridiculizar la religión católica por todos los medios propios de la masonería. ${ }^{5}$

La insistencia de El Católico en mostrar la vinculación de $E l$ Porvenir con la masonería salvadoreña, y en particular con Rafael Reyes, es significativa, pues aunque ciertamente Reyes era masón, ${ }^{6}$ no hay indicios de que el periódico se identificara a sí mismo como el "órgano de la masonería" y menos que se señalara a Rafael Reyes como su redactor. De hecho, la estrategia desarrollada por este primer comentario era aportar evidencia indirecta que convenciera al lector del involucramiento de Reyes en la elaboración de El Porvenir, es decir, realizando un somero análisis y comparación con los artículos ya publicados y firmados por él, en los que abundaban los temas anticatólicos. Sin embargo, cuando el Juzgado Segundo de Primera Instancia de San Salvador Ilamó en Septiembre a declarar al "Editor responsable" de El Porvenir, nunca se mencionó el nombre de Rafael Reyes - y mucho menos compareció ante el tribunal-, sino Silverio Angulo Guridi ${ }^{7}$, alias "Lewis" ${ }^{8}$ o también conocido como Silverio Angulo Lewis, ${ }^{9}$ de quien al momento no existe evidencia de que haya sido masón.

En posteriores comentarios, y a medida que las causas judiciales en contra de El Porvenir iban avanzando, El Católico tuvo que cambiar su discurso, pero siempre insistirá en mostrar las vinculaciones del periódico con la masonería salvadoreña, especialmente con la Logia "Excélsior $n^{\circ} 17$ " y con Reyes. El motivo de esta nueva vinculación con Reyes fue la reproducción que hizo el periódico guatemalteco Las Noticias de algunas de las denuncias 


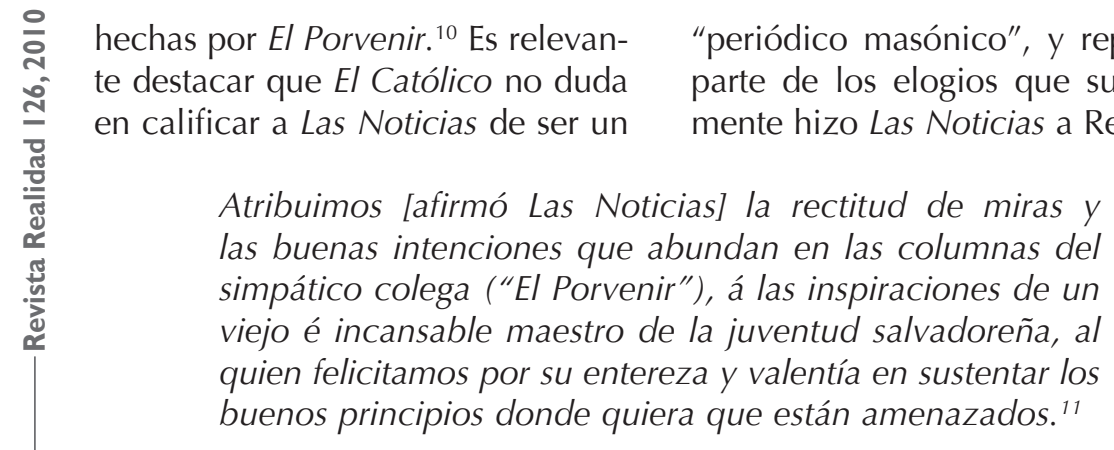

Estas líneas le servirán a El Católico para afirmar que "no es, pues, solo la opinión pública, no es solo 'El Católico', sino el diario 'Las Noticias', que en materias masónicas merece plena fe, quien atribuye [a Reyes] la rectitud de miras..." de EI Porvenir; y añade: "Es á él [Reyes] á quien la masonería de Guatemala felicita, más que á los mismos Redactores de "El Porvenir", por su entereza y valentía en sostener los buenos principios". ${ }^{12}$ Pero ante la falta de pruebas contundentes de la participación directa de Reyes, El Católico, sin dejar de reconocer su influencia o ascendencia sobre los verdaderos Redactores, tuvo que admitir la existencia de algunas diferencias fundamentales entre el estilo de redacción de Reyes y el desarrollado en El Porvenir:

Sin embargo, creemos que el maestro ni escribe ni está en perfecto acuerdo con "El Porvenir, en cuanto á la forma y materia de sus artículos. No escribe, porque el estilo dominante de "El Porvenir" es recto hiriente, el del maestro es oblícuo, curso, suave... Tampoco en el fondo; por que "El Porvenir" prefiere los hechos á los principios, lo personal á lo doctrinario; el maestro al contrario, prefiere los principios á los hechos, lo doctrinario á lo personal. Ha sucedido con "El Porvernir" lo que ordinariamente sucede; que los discípulos salen más aventajados que el maestro; que los conductores no siempre pueden contener á los conducidos en el punto que quieren. ${ }^{13}$

Con todo, las afirmaciones de El Católico en contra de Reyes y sus escritos constituyen un excelente resumen de las críticas teológicas que los liberales secularizantes y masones del siglo XIX lanzaban en contra de la religión y la teología católica. Nótese, sin embargo en el texto siguiente, la contundencia con que en estas líneas -publicadas en Junio- $E I$ Católico sostiene la similitud entre lo escrito por Reyes y por El Porvenir: ${ }^{14}$ 
Siendo el Doctor Reyes, quien inspira, ordena y dirige dicho quincenal, nadie extraña encontrar reproducidos en sus columnas los mismos, mismísimos sofismas publicados por él en mil ocasiones, y las mismas, mismísimas defensas y propias alabanzas, salidas otras veces de su propia pluma. Por eso campean en el primer número de "El Porvenir" el absurdo de uno igual á tres, como el Dr. Reyes ha llamado al misterio católico de la Trinidad; el de la Virgen madre de un hijo, como ha llamado al misterio de la divina maternidad; el absurdo de que el hombre se coma á Dios, como el Dr. Reyes ha dicho de la sagrada Escritura; la idolatría de adorar á los palos, como ha dicho de la veneración de las imágenes; la leyenda Bíblica; la fábula de la divinidad de Jesucristo, etc., etc., etc. ${ }^{15}$

Para El Católico, el objetivo último de denunciar las actuaciones de Reyes se debía a que estaba utilizando su cátedra de Derecho Natural impartida en la Universidad de El Salvador para atacar a la religión y la teología católica. En otras palabras, el semanario ultramontano "respetaba" que el Doctor Reyes utilizara las páginas de El Porvenir para exhibirse públicamente como "libre-pensador" y para atacar al catolicismo, en virtud del "derecho" a la "libertad de ex- presión de ideas" que le garantizaba la Constitución de 1886; y lo mismo podía decirse de las enseñanzas masónicas que impartía en la Logia, en su calidad de "maestro masón" y en virtud del "derecho de libre enseñanza" también garantido en la Constitución; pero lo que no se podía tolerar, a juicio de El Católico, era que Reyes utilizara su cátedra universitaria, una cátedra pagada por un Estado oficialmente laico, para atacar una religión concreta:

Decimos que es ilegal [los ataques de Reyes a la religión], porque el Profesor oficial que ataca las creencias de la religión en su cátedra, viola la ley de instrucción pública. En efecto, dicha ley prescinde solamente en sus programas de la enseñanza religiosa; esto es, se limita al silencio acerca de las creencias. Pero de ninguna manera permite, ni mucho menos manda, que se impugnen y ataquen los misterios de la religión. Prescindir de la religión en las clases oficiales, es acto puramente negativo; es una omisión que deja á los alumnos conservar las creencias aprendidas en el hogar de su familia; pero impugnar la religión desde la cátedra oficial, es un acto positivo, una acción eficaz, que arranca de la juventud la fé aprendida por sus padres. Por 
consiguiente, el profesor aludido [Reyes] se excede, hace lo que la ley prohíbe, atacando aquello de que debe prescindir, y enseñando positivamente otra religión contraria á aquella cuyos dogmas impugna. ${ }^{16}$

Pero que el Profesor de Derecho Natural de la Universidad pretenda hacer lo mismo en las aulas nacionales, es un atentado y no puede hacerlo; porque allí es un empleado público, un funcionario oficial, pagado por el Gobierno no para ejercer derechos, sino para cumplir obligaciones... Pero que el Doctor Reyes pretenda explotar el Tesoro público, parapetarse con la Universidad Nacional, autorizarse con el nombramiento del Gobierno, abusar de la enseñanza oficial para insultar la religión profesada por la casi totalidad del pueblo salvadoreño, es pretender humillar y poner bajo sus pies las más nobles instituciones de la República... ${ }^{17}$

De hecho, antes de que apareciera El Porvenir, El Católico ya venía quejándose de que Reyes estaba utilizando sus clases para atacar al catolicismo. Así, en la edición del 8 de Mayo, denunció que era "público" que Reyes dedicaba su cátedra "para difundir entre la juventud los errores más contrarios á la Iglesia católica" ${ }^{18}$ e incluso se detalla que "en uno de los días pasados, empleó casi toda la hora de clase, en exponer la fábula o leyenda de la Divinidad de Jesucristo" ${ }^{\prime 19}$

En respuesta a este comentario, se publicaron en los periódicos El Correo Nacional y El País ${ }^{20}$ dos "Remitidos" firmados por alumnos de Reyes -a los que no se ha tenido acceso- en los que se le defendía de los ataques de El Católico. El remitido en El País, firmado por "Unos Estudiantes", reconocía que aunque Reyes "sea contrario en convicciones respecto á este asunto (la Divinidad de Jesucristo) como en realidad lo es, sabe respetar como todo liberal, las doctrinas de sus contrarios". ${ }^{21}$ Es más, calificó a Reyes como un "digno representante del racionalismo", y añade que "las opiniones emitidas por un profesor racionalista no pueden contribuir en manera alguna, en desmoralizar la juventud salvo que no se entiende lo que es el racionalismo". ${ }^{22}$

El Católico, por su parte, publicó un Remitido escrito por otro de los estudiantes que asistían a la Cátedra de Derecho Natural que impartía Reyes, y pone en entredicho los contenidos de los dos ya mencionados que buscaban "vindicar la conducta que el Dr. Reyes observa en las clases que tiene á su cargo". ${ }^{23}$ Este documento está firmado por "Arturo", quien se identifica a así mismo como "Estudiante de 
Jurisprudencia", y destaca con extrañeza que el Remitido publicado en El Correo Nacional solo haya sido firmado por nueve estudiantes, cuando los que asistían a las clases de Reyes eran "más de treinta". Y por si fuera poco, "Arturo" denuncia que fue el mismo Reyes quien promovió entre los estudiantes la elaboración del Remitido publicado en El Correo Nacional: "los jóvenes firmantes se vieron en el compromiso de dar sus firmas, porque el Dr. se las pidió en los momentos de clase y no tuvieron la firmeza de carácter suficiente para negársela, como lo hicieron sus otros compañeros"; y aclara que de los nueve que lo firmaron, "uno se la dio porque el Sr. Reyes le ofreció que no se publicaría el remitido". ${ }^{24}$

Pero la controversia levantada por las opiniones de Rafael Reyes respecto de la divinidad de Jesucristo no terminó aquí, pues en ocasión de las Fiestas Patronales de San Salvador, el 6 de Agosto, cuando se celebra la Transfiguración de Jesús en el Monte Tabor, el Obispo de San Salvador, Adolfo Antonio Pérez y Aguilar, publicó una Carta Pastoral en la que abordó precisamente el tema de la divinidad de Jesús, y no desaprovechó la oportunidad para condenar al Libre-pensamiento, al Racionalismo, al Naturalismo, al Materialismo y al Ateísmo (y por supuesto a los seguidores de todas estas corrientes de pensamiento), a los que calificó de "sistemas de invención humana, ineptos y viciosos" y como "los principales y más funestos errores del día, producto de la rebelión sistemática contra las doctrinas del Evangelio y divina autoridad de Jesucristo".$^{25}$ En consecuencia, pidió a sus feligreses que se guardaran de "su maléfica influencia que pervertiría fácilmente la sencillez y pureza de vuestras creencias"; y además sugirió a los fieles poner "a cubierto vuestras familias de la activa propaganda que de ellos se hace por medio de libros, folletos y periódicos, sin otro fin que el muy pernicioso de desarraigar las creencias católicas del corazón de los pueblos, y poner en sus manos como único recurso para su mejora y moralización, el espíritu de resistencia á toda ley y sus naturales tendencias á la corrupción $y$ al vicio" ${ }^{26}$

Esta Carta Pastoral desencadenó un nuevo intercambio de artículos entre ambos periódicos. Según detalló El Católico, El Porvenir "tuvo la feliz ocurrencia de refutar la hermosa pastoral sobre la divinidad y magisterio de Jesucristo, que el Ilustrísimo señor Obispo publicó á principios de este mes con ocasión de la fiesta del Divino Salvador"; ${ }^{27}$ y aclaró por qué —a su juicio- se trataba de una "feliz ocurrencia", lo que lo llevó a dar algunos detalles sobre este nuevo escrito anticatólico. 
Dicho artículo ocupa las dos terceras partes del periódico, esto es, ocho de sus largas columnas; casi triple extensión de la de la pastoral. Así debía ser para que cupiesen tantos y tan repetidos apodos, insultos, burlas, injurias personales al Ilustrísimo señor Obispo, tantos y tan repetidos disparates y tonteras sobre la doctrina cristiana. ${ }^{28}$

Sin embargo, el texto no reproduce cuáles eran esos apodos, insultos, burlas e injurias personales en contra del Obispo, ni los repetidos disparates y tonteras sobre la doctrina cristiana y que cualquier niño en catequesis podría fácilmente refutar. En cambio, se limita a afirmar que:

Aunque la pastoral del Ilustrísimo Prelado no sea otra cosa que la fiel exposición del Evangelio y el comentario exegético de los textos de la Sagrada Escritura relativos á la divinidad y enseñanza del Divino Salvador, sin embargo, ese Evangelio y esos Libros Sagrados que todos acatan como inspirados por Dios, como la palabra divina, para los redactores de "El Porvenir" son mentiras, absurdos y errores. Los libre-pensadores son tan sabios y tan ilustrados, principalmente en religión, que siempre están listos para discutir con todos juntos los prelados de la Iglesia, y hasta para refutar al mismo Jesucristo y al mismo Dios si se les pone enfrente. ${ }^{29}$

Para concluir esta parte, digamos que en el primer comentario y ataque a El Porvenir por parte de El Católico, éste anunció que su conducta respecto del nuevo impreso sería el mismo que la prensa católica española mostraba respecto de los periódicos masónicos y promasónicos, tales como Las dominicales del Libre Pensamiento o EI Motín: "jamás los mienta, jamás se ocupa de ellos"; y añade:

"El Porvenir" servirá a la opinión pública, para que por el futuro conozca el árbol que lo produce; para que por las opiniones del discipulado, sepa apreciar las enseñanzas del Maestro; o como dijo un estudiante, "por la pluma se conoce el tordito". ${ }^{30}$ 


\section{Nuevos ataques de El Porvenir al catolicismo y acciones judiciales en su contra.}

No obstante la promesa solemne de parte de El Católico de ignorar a El Porvenir, el propósito no se pudo mantener en el tiempo, aunque se debe reconocer que hizo todo lo posible por cumplir la palabra empeñada durante los siguientes dos meses. Pero los ataques a la Iglesia salvadoreña por parte de El Porvenir continuaron arreciando hasta que en la edición del 7 de agosto, El Católico publicó una nota de protesta firmada por los miembros del Cabildo Eclesiástico por las calumnias publicadas en el periódico en contra del papado, del obispo salvadoreño, Adolfo Antonio Pérez y Aguilar, y de algunos miembros del clero secular. La protesta del Cabildo estaba fechada el 3 de agosto, y en su parte medular se afirma lo siguiente:

Considerando $1^{\circ}$ - Que el periódico titulado "El Porvenir" tiene por único objeto combatir nuestra Santa Religión y deshonrar sus ministros por cuantos medios sugiera la pasión; Considerando $2^{\circ}$ - Que en el número 5 de dicho periódico, correspondiente al 31 de Julio, se calumnia á la venerable memoria del Sumo Pontífice Inocencio III y á la Santa Sede Apostólica, se injuria gravemente al Ilustrísimo señor Obispo de esta diócesis y se difama á varios sacerdotes salvadoreños imputándoles delitos atroces... Acuerda: $1^{\circ}$ - Protestar, como en efecto protesta con toda la energía de su alma, contra los errores y ofensas inferidas por El Porvenir á la Santa Iglesia Católica y al Soberano Pontificado, contra sus injurias al dignísimo Prelado de esta diócesis y contra su difamación de varios sacerdotes salvadoreños... ${ }^{31}$

Nótese que el Cabildo Eclesiástico no hizo ninguna conexión entre el periódico y la masonería, tal y como lo venía haciendo de manera insistente El Católico; y tampoco entró en detalles sobre el contenido de las supuestas difamaciones. En realidad, fue El Católico quien fue ofreciendo aquí y allá detalles de lo publicado y/o denunciado por $E I$ Porvenir. Algunas de ellas eran en verdad graves: a) que un sacerdote había violado a una joven en el cementerio de San Salvador; ${ }^{32}$ b) que el Agente General de El Católico, Federico Prado, habría "reprendido y aun quiso golpear á uno de los muchachos repartidores del periódico" [de El Porvenir]; ${ }^{33}$ c) se acusó al Sacerdote de origen italiano, Miguel Vecchiotti, Vicario de la Diócesis y miembro del Cabildo Eclesiástico, de haber casado en dos ocasiones a un compatriota suyo, promoviendo 
así y encubriendo al mismo tiempo, un acto de bigamia; ${ }^{34}$ y d) al Obispo de la diócesis, se "le imputa el haber despojado á un hermano del difunto Padre (Vicente) Marroquín del fruto de su trabajo de once años en una finca del mencionado Padre, y el habérselo apropiado injusta é inícuamente" ${ }^{\prime \prime} ; 5$ e) de acuerdo con $E I$ Católico, El Porvenir también atacó a las Hermanas de la Caridad que trabajaban en la ciudad de Santa Ana y a un Sacerdote que también residía en esa ciudad, sin embargo, no se dieron mayores detalles del contenido de estos ataques y lo único que se puede colegir es que El Porvenir sostenía que una de las Monjas había mantenido relaciones sexuales con el Sacerdote; ${ }^{36}$ y f) también se atacó a un Padre de apellido Funes, quien finalmente acudió a un Tribunal de Justicia y acusó a El Porvenir por difamación. ${ }^{37}$
En su edición del 25 de septiembre, El Católico comenta un artículo aparecido en La vOZ de Cuba en el que se analizaba por qué la prensa atacaba al clero de la todavía entonces colonia española. La razón era clara: demoler las bases de la sociedad para procurar subrepticiamente el advenimiento del Socialismo: "Sus detractores [del clero, afirmaba La voz de Cuba] no se proponen un fin generoso $y$ noble; es un fin de bastarda política y de soéz socialismo". ${ }^{38}$ A renglón seguido, El Católico comparó la actuación de la prensa cubana con la llevada a cabo por El Porvenir en El Salvador, y al hacerlo hizo un resumen y balance de todos los ataques que El Porvenir había lanzado en contra del clero y la Iglesia. Este resumen nos permite barruntar la magnitud de la crítica desplegada a lo largo de sus ediciones:

Ha difamado personalmente y en lo más apreciado, al Ilustrísimo señor Obispo, al señor Vicario General, á los Canónigos del Cabildo Eclesiástico, á más de veinte sacerdotes que desempeñan la administración parroquial ú otros cargos sagrados; hasta á las mismas Hermanas de Caridad, respetadas entre la soldadesca y entre los bárbaros. ¿Y con qué medios los ha difamado? Con las calumnias más negras, con las injurias más soeces, con falsificaciones de firmas, con suplantaciones, con apodos de taberna, con las imputaciones más ridículas. ${ }^{39}$

Voy a exponer por separado el contenido de algunas de estas acusaciones y la respuesta que dio a ellas El Católico. Advierto nuevamente que dado que no disponemos de los ejemplares de $E I$
Porvenir, reconstruyo sus denuncias y críticas a partir de los datos que proporciona la versión -interesada, como era de esperar- de una de las dos partes en contienda. 
a. Violación de una señorita en el Cementerio de San Salvador por parte de un sacerdote

Respecto de la supuesta violación de la muchacha por parte de un sacerdote, El Católico reprodujo unas líneas de lo publicado por EI

Porvenir, que le servirá para mostrar la falsedad de la denuncia. Así reza el texto de El Porvenir reproducido:

En Centro-América, en el corazón del Nuevo Mundo, en la República del Salvador, en la capital de la Nación á los términos del siglo XIX y á la luz del día, un sacerdote ha conducido á una señorita al recinto del cementerio, y allí, sobre el horror sagrado de los sepulcros, la ha deshonrado". ${ }^{40}$

A continuación, El Católico rechazó la acusación de manera tajante y se esforzó por mostrar que nunca se realizó la violación y que el supuesto sacerdote en realidad no lo era, sino un "seglar", aunque tuvo que admitir que efectivamente había sido seminarista hasta hacía un mes antes de ocurrir el incidente:

Tenemos a la vista la nota del señor Ministro de Gobernación, dirigida al Ilustrísimo señor Obispo en los primeros momentos del suceso, y la contestación del Ilustrísimo Prelado tan pronto como hizo las averiguaciones y tomó los informes correspondientes del Custodio del Cementerio. Resulta que el supuesto sacerdote es un verdadero seglar; que no ha recibido ni siquiera la primera tonsura, que es la puerta para entrar al clero. Resulta que es un simple exseminarista, que salió del colegio hace un mes, habiendo recibido orden de dejar el uniforme, del que usaba indebidamente. Resulta además, que es enteramente falsa la supuesta deshonra de la señorita sobre el horror sagrado de las tumbas y que, según el testimonio del sepulturero, no hubo el más pequeño acto que pudiera hacer sospechosa la moralidad de ambos; que la orden de captura contra ellos se motivó solamente en la razón de estar solos conversando en el Cementerio, lo que en realidad no constituye delito. Todo esto se esclareció en el acto y fueron puestos en libertad. He aquí todo el bombo y toda la farsa, con que se ha pretendido la afrenta del clero salvadoreño. ${ }^{41}$ 
Aclarada la situación respecto de la supuesta violación, a continuación, El Católico no desaprovechó la oportunidad para atacar una vez más a Rafael Reyes y de hacerlo responsable de haber difundido y magnificado injustificadamente la noticia:

Se dice que el primero que llegó a la casa de la apreciable familia de la referida señorita, para hablar con la madre y hermanas é informarse de todo, fue el I.: H.: masón, que en el Salvador es reconocido como primer caudillo de los ataques contra la Iglesia. Allí dió el pésame á la familia, lamentó el suceso, se condolió profundamente por lo ocurrido, deseó que todo se terminase pronto \&. \&. \&.\&. ${ }^{42}$

A continuación insiste en establecer nuevamente una conexión directa entre El Porvenir y Rafael Reyes: "Sabido es también que el mismo Poderoso Hermano es el alma y la inspiración, el oculto director y jefe de los escritores de 'El Porvenir'"'; y aprovecha la ocasión para destacar el distanciamiento que existía entre Reyes y el Presidente de la República, Carlos Ezeta, ${ }^{43}$ cuya condición masónica también era pública: ${ }^{44}$ "Sabido es que ese Hermano Ilustre, aunque no tiene cabida oficialmente en el Gobierno ni privanza con el señor Presidente, sí tiene poderosos amigos en el Gobierno á donde por su medio hace llegar y conseguir lo que quiere" ${ }^{45}$

El Católico nunca llegó a revelar el nombre del supuesto violador; sin embargo, El Porvenir todavía a mediados del mes de Septiembre seguía insistiendo en la veracidad del hecho y que el hechor no habría sido un ex-seminarista, sino el Sacerdote Miguel Echeverría. ${ }^{46}$ Sin duda la sensibilidad contemporánea respecto de estos temas que han arrastrado a la Iglesia católica a muchas denuncias por abusos sexuales ha evolucionado radicalmente, y en ese sentido no deja de llamar la atención la postura pública un tanto ambigua que mostró El Católico respecto de la manera de tratar estos casos. Al inicio de todo este asunto, rechazó vigorosamente que el obispo hubiera ocultado las actuaciones de sacerdotes que incurrieron en ilícitos como los denunciados por El Porvenir:

Con los mismos medios y con mayor escándalo se difama á varios sacerdotes salvadoreños, atribuyéndoles delitos atroces en su vida privada y aún prevaricaciones en el sagrado tribunal de la penitencia; se agrega que la Autoridad eclesiástica ha dejado impunes esos delitos, y que aún los ha recompensado, colocando á los culpables en puestos 
honrosos. Jamás la autoridad eclesiástica se ha hecho cómplice por la impunidad ó recompensa de las faltas que los sacerdotes pueden cometer. Muy al contrario; ha sido siempre la primera en investigar, juzgar y penar, las sometidas á su conocimiento, en las pocas veces que algún sacerdote ha sido vencido en juicio. ${ }^{47}$

Sin embargo, unas semanas más tarde, El Católico explica por qué consideraba como lo más correcto

ocultar del escrutinio público actos como los denunciados, aunque fueran verdaderos:

"El Porvenir" ha referido tales historias de dichos sacerdotes, que, aun suponiéndolas verdaderas y ciertas, deberían cubrirse y ocultarse, sinó por consideración al clero, al menos por respeto á la sociedad y por el decoro propio de quien las refiere. Pero el periódico masónico no entiende nada de esto; al contrario, ha lanzado á la publicidad sus asquerosas calumnias con detalles tan impúdicos, con términos tan deshonestos, en estilo tan escandaloso, con equívocos tan lúbricos, que bien revela su desprecio por la sociedad, por la familia, por el decoro de las mujeres, por la inocencia de los niños á quienes pueden llegar sus hojas envenenadas. ${ }^{48}$

Personalmente me Ilama la atención la forma escandalizada en que El Católico alude a la manera en que El Porvenir manejaba las noticias de este tipo; podríamos aventurarnos a decir que El Porvenir lo hacía buscando explotar cierto "sensacionalismo" o morbo, estrategia que muy probablemente buscaba atraer a un número mayor de lectores. Como ha sugerido Ricardo Roque-Baldovinos, este nuevo estilo de elaborar la noticia venía introduciéndose en El Salvador, desde finales de la década de los 80 del siglo XIX, y se ensayó con bastante claridad en el periódico La Unión, dirigido por Rubén Darío, y que circuló dos años antes que El Porvenir:

El periodismo de El Salvador hacia 1889 tenía una larga e importante trayectoria en la vida política nacional... Era, sin embargo, un periodismo muy distinto de los de hoy. Se había incubado en las contiendas políticas y más que entregar "noticias" entregaba ideas: alegatos en favor o en contra de cierto partido o personalidad política; o, en todo caso, transmitía información muy básica y práctica... En 
buena medida, La unión seguirá todavía el formato y los géneros discursivos del periodismo tradicional de ideas, pero dará vistosos y atrevidos saltos hacia lo nuevo. Las cuatro páginas de gran formato que este periódico debe llenar a diario demandan, sin embargo, más información. Y aquí sus redactores comienzan a dar pruebas de gran inventiva. De manera progresiva, no sólo reaccionan con opiniones meditadas al acontecer político como era la costumbre, sino que comienzan a dar noticias sobre el acontecer nacional y, van todavía más allá al comenzar a crear sucesos mediáticos, algunos de los cuales carecen de relevancia política pero buscan captar la atención de los capitalinos, explotando el morbo en lo truculento y escabroso, con los tópicos propios del periodismo sensacional moderno. ${ }^{49}$

Es muy probable que el debate entre El Porvenir y El Católico respecto de la manera "sensacional" de abordar ciertas noticias o de "crear suceso mediáticos" nos refleja que este proceso de transformación, del que habla Roque-Baldovinos, estaba extendiéndose en el periodismo salvadoreño, y que lo alejaba del tradicional "periodismo de ideas" o más político e impersonal, más propio de un liberalismo que juzgaba como región sagrada o vedada al escrutinio público la vida privada de los ciudadanos, a un periodismo que explota "el morbo en lo truculento y escabroso". Quizás por ello, El Católico siempre insistió en que lo que El Porvenir buscaba era más bien azuzar el sensacionalismo, que evitar que situaciones tan lamentables como las relatadas se volvieran a repetir:

Si los escritores de "El Porvenir" se propusieran otro fin diferente de la difamación del clero salvadoreño, harían sus denuncias ante las autoridades, civiles o eclesiásticas, Ilamadas á juzgar é imponer las penas á las acciones privadas ó delitos. Pero escandalizar al público con relatos hechos ad hoc, revestirlos de circunstancias de sensación, y sin pruebas ni testimonios entregar al escarnio y al desprecio de la sociedad á las víctimas de su pasión, son medios y armas reprobados por la moral y por la conciencia. ${ }^{50}$

Con todo, en mi opinión, El Porvenir en el fondo seguía desarrollando un periodismo político, es decir, concebido para atacar o denigrar al adversario político, que en este caso seguía siendo la Iglesia católica. 
b. Ataque a uno de los repartidores de El Porvenir por el Agente General de El Católico

Como ya adelantaba, a Federico Prado, Agente General de El Católico desde su fundación en 1881, El Porvenir le acusó de haber "reprendido y aun quiso golpear á uno de los muchachos repartidores del periódico". El Católico respondió afirmando que Prado había negado la acusación, y aseguró que "no ha visto ni hablado jamás á ningún repartidor de "El Porvenir", y aclaró que por motivos de salud había estado ausente de la Capital durante el mes de Julio, es decir cuando comenzó a circular el nuevo periódico. Sin embargo, El Católico comentó sobre los epítetos que El Porvenir había utilizado para referirse al Agente General del semanario ultramontano, que de ser ciertos, reflejan la virulencia de los ataques de El Porvenir en contra de Prado:

Por lo que hace á los insultos, ridículos y ofensas que dirige al señor Prado, como llamarle negociante de caridades que le dejan cuantiosas utilidades,... pseudo jesuita..., solípedo... \&, \&.; creemos que no llegan á la altura, donde ese apreciable caballero ha puesto su nombre ante la sociedad. ${ }^{51}$

c. Acto de bigamia consentida y ocultada por el Vicario de la Diócesis

Al Sacerdote italiano Miguel Vecchiotti, Vicario de la Diócesis y miembro del Cabildo Eclesiástico, El Provenir lo acusó de haber casado por la Iglesia en dos ocasiones a un compatriota suyo. En otras palabras, lo acusó de consentir un acto de bigamia. A continuación la transcripción que hizo El Católico del texto de El Porvenir:

Al pastor Vecchiotti preguntamos de pies á cabeza, como se llama el Canónigo italiano que casó á un paisano dos veces consecutivas á sabiendas de la fechoría, y, á la segunda esposa del bígamo se negó á darle, con la certificación del primer matrimonio de éste el único medio con que contaba la infeliz mujer, para perseguir ante los tribunales á su criminal marido. Digan el Pater Vecchiotti y el público imparcial si el Canónigo italiano es hombre venerable. No es hombre venerable el que, además de cometer esa acción infame, tiene el ridículo apodo de Fray Vejiga". ${ }^{52}$ 
En este caso, sin embargo, El Católico no hizo ningún esfuerzo por aclarar el incidente, como lo había hecho con las dos acusaciones ya mencionadas, y como lo hará con toda su energía en el caso de la acusación del Obispo. Simplemente se limitó a destacar las grandes virtudes del sacerdote cuestionado, a hacer un breve resumen de su carrera eclesiástica en el país, su gran compromiso con la causa católica a pesar de la persecución masónica y liberal, $y$ en ese sentido se congratula de que Vecchiotti sea una vez más atacado por los masones, pues prueba que su compromiso con la defensa de la fe no había claudicado:

"El Porvenir" ha creído que con viles calumnias y con vulgares apodos, apagaría la brillantez de esos méritos y á rasgar los títulos de ese benemérito sacerdote á la gratitud del pueblo salvadoreño. Es el mochuelo que intenta apagar el sol. Decimos más; "El Porvenir" con sus calumnias y apodos ha venido á completar, sin quererlo, la verdadera gloria de la virtud en el señor Vecchiotti, que se compone del doble tributo que le rinden los hombres; esto es, las bendiciones y el amor de los buenos, la maldición y el odio de los perversos. Felicitamos á nuestro digno señor Provisor, Canónigo doctor Vecchiotti, al verlo colocado sobre el pedestal, que la masonería y el libre-pensamiento erigen con sus blasfemias á los dogmas sacrosantos de nuestra fé, a los más ilustres Pontífices, á los más virtuosos Obispos y a los más ameritados sacerdotes del catolicismo. ${ }^{53}$

\section{d. Acusaciones en contra del Obispo salvadoreño Antonio Adolfo Pérez y Aguilar y las consecuencias judiciales de este ataque}

Sin embargo, las acusaciones de El Porvenir que levantaron mayores protestas de parte de los católicos más militantes y que llegaron a los Tribunales de Justicia fueron las que se dirigieron en contra del Obispo, pues, según lo formuló El Católico mismo, el objetivo de $E I$ Porvenir era, en última instancia, presentar al Obispo "como ladrón, injusto, avaro é inícuo, ante sus diocesanos". ${ }^{54}$ Es la que voy a analizar con un poco de más detalle, dada la gravedad del asunto y las implicaciones judiciales que tuvo.

La acusación en contra del Obispo se publicó en el número 5 de El Porvenir, correspondiente al 31 de Julio, según indicó la nota de Protesta del Cabildo Eclesiástico, fechada el 3 de Agosto; sin embargo el Cabildo no dio detalles sobre la acusación, sino que fue en nota adjunta de El Católico que se hizo una primera aproximación a la mis- 
ma. Allí se da cuenta de una Carta abierta dirigida al Obispo, publicada por El Porvenir, fechada en el Municipio de Jayaque y firmada por Miguel Quiñónez, abogado del ofendido, en el que acusa al Obispo de "haber despojado a un hermano del difunto Padre Marroquín" (Benito Marroquín), la herencia que legítimamente le habría legado si se le hubiera permitido a su hermano que se acercara a su lecho de muerte, cosa que según la carta, el Obispo impidió. ${ }^{55}$

En este primer momento, El Católico asume que la carta de Quiñónez era legítima — cosa que se pondrá en duda un poco más adelante-y por ello se pregunta: ipor qué Quiñónez, en lugar de acudir a El Porvenir, no acudió "á los tribunales comunes, ante los cuales el Ilustrísimo Señor Obispo, suprimido el fuero eclesiástico entre nosotros, es igual á todos los salvadoreños"?, o si el difunto Vicente Marroquín, "al hacer su testamento ante el cartulario Dr. don Balbino Rivas, no reconoció derecho alguno á su hermano en la finca mencionada, ¿por qué pretende que el Ilustrísimo Señor Obispo, á fuer de Prelado, cambie el destino que la voluntad del testado dio á sus bienes, y los entregue como pago á su defendido o poderdante?"56

En su edición del domingo 21 de agosto, El Católico obvió toda referencia a El Porvenir o a las acusaciones en contra del Obispo, pero dos días después, el martes 23 se publicó un "Alcance" a la edición del pasado día 21, titulado "Calumnia descubierta", que contenía una "carta importante" firmada por Miguel Quiñónez, fechada en la población de Tepecoyo —no en Jayaque - el 19 de agosto. Junto a la carta, El Católico adjuntó algunas reflexiones y consecuencias que se podían sacar de la misma. ${ }^{57}$ Este "Alcance" se reprodujo junto con las apreciaciones de El Católico en su edición del 28 de agosto, argumentando que se había "agotado la edición del Alcance...", y para así poder "enviarlo á todos lo suscriptores y á los periódicos que nos honran con su canje". Añade la breve nota, que el original de la carta de Quiñónez estaba "en la Redacción de El Católico, para que puedan verla todos los que lo deseen". ${ }^{58}$

Pero yendo, en primer lugar, a la carta dada a conocer por El Católico, en ella Quiñónez sostiene que jamás escribió la misiva publicada en El Porvenir, y por ende acusa a los redactores de El Porvenir de haber "falsificado mi firma", y en consecuencia, dado que se trataba de "un documento de tanta gravedad, á vista de los salvadoreños, lo denuncio formalmente ante el público y ante los tribunales de la República, para que las autoridades respectivas, de oficio, hagan recaer el peso de la ley sobre semejantes criminales, por ser ellas el poderoso baluarte de las garantías del hombre honrado". ${ }^{59}$ A continuación, Qui- 


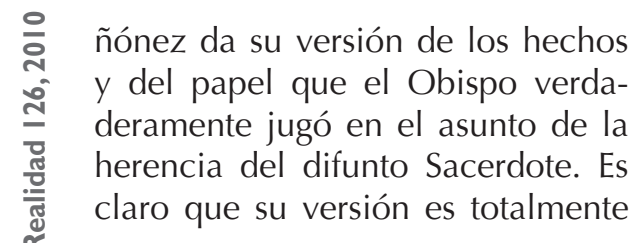

contraria a la expuesta por El Porvenir, y el Obispo salió bien librado de las acusaciones que se le imputaban, como lo destacó El Católico en sus comentarios adjuntos:

Que la Carta abierta, publicada en "El Porvenir", dirigida al Ilustrísimo señor Obispo de esta Diócesis, injuriándolo y calumniándole públicamente y con el mayor cinismo, es obra propia de los redactores de "El Porvenir", que sin respetarse así mismo y burlándose de la sociedad, usan de los medios más viles contra sus adversarios. ${ }^{60}$

En otra parte de la Carta, Quiñónez comenta algunos detalles del incidente que servirán a $E /$ Católico para involucrar no solamente a $E I$
Porvenir en todo el asunto, sino también a algunos masones salvadoreños. Trascribo a continuación este fragmento de la Carta:

\begin{abstract}
Hará cerca de tres meses que fuí á esa capital (por negocios propios) y cierto sugeto á quien no conozco, se me presentó diciéndome; que el señor don Guillermo Dawson era á propósito para desempeñar y poder reclamar los bienes y derechos de don Benito Marroquín; me hizo que compareciera ante el señor Dawson; y éste, habiéndome hecho algunas preguntas sobre el asunto de Marroquín, me dijo: que me llamaría para tomarme una declaración, á cuya indicación le contesté: que yo declararía las justas observaciones que sobre este asunto nos hizo el Ilustrísimo señor Obispo. ${ }^{61}$
\end{abstract}

La referencia a Guillermo Dawson es crucial, pues aunque $E I$ Católico no lo afirma, no cabe duda de la condición masónica de Dawson, como se puede comprobar por la ficha que se conserva de él en Archivo Masónico del Supremo Consejo de Centro América. De acuerdo con la ficha, ${ }^{62}$ la Logia Madre de Guillermo Dawson fue la "Excélsior N ${ }^{\circ} 17$ " de San Salvador, donde recibió el Grado 1 el 26 de
Agosto de 1887, el Grado 2 el 16 de Diciembre de ese mismo año, y el Grado 3, el 4 de Abril de 1888. Además, la condición masónica de Dawson también era pública, pues el periódico El dos de Abril había puesto su nombre en la lista de masones que colaboraban en el gobierno de Menéndez. ${ }^{63}$ Durante 1891, Dawson aparece desempeñando funciones como "tenedor de libros" en la Dirección General de 
Rentas, ${ }^{64}$ como profesor de Inglés del Instituto Nacional de Secundaria, ${ }^{65}$ y de acuerdo con El Católico también era propietario de un periódico denominado El Fiscal, al cual no duda en calificarlo de "obsceno". ${ }^{66}$ Pero veamos en qué términos El Católico asoció este pasaje de la Carta de Quiñónez con la supuesta actuación de algunos masones:

Que en todas las mentiras y calumnias de "El Porvenir" á la Iglesia y al Clero está siempre oculta, siempre traidora, la mano masónica del que maquina continuamente por destruir las creencias católicas en el pueblo salvadoreño. ¿Quién es, en efecto, ese personaje misterioso, tan acomedido, tan servicial, tan activo y tan conocedor del asunto del P. Marroquín y de las personas más á propósito para desempeñarlo?... El que aconseja, el que trama, el que dirige un delito es más criminal que el que lo obedece y ejecuta!!!67

El Católico termina sus reflexiones sobre el contenido de esta Carta con las siguientes afirmaciones: " Estos son los hombres del libre pensamiento! ¡Estos son los hombres de la masonería! Estos son los que se Ilaman redentores del pueblo, apóstoles del progreso, maestros de la verdad moral y de la verdadera virtud!"68

En la edición del 4 de septiembre, El Católico reportó que El Porvenir había respondido "con un
Alcance á su número 6", al propio de El Católico. En él, El Porvenir reveló la existencia de "una segunda carta al Redactor de 'El Porvenir'", firmada por Miguel Quiñónez, en la que descalifica como apócrifa la que apareció en el "Alcance á 'El Católi-

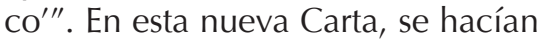
al Obispo "nuevas y más graves injurias" ${ }^{69}$ El Católico reprodujo una breve porción de la referida segunda carta de Quiñónez en la que se describe cómo el Obispo supuestamente había amenazado a Quiñonez:

... declara su firma suplantada por la gente de Sotana y su persona en la villa de Tepocoyo; califica de falsario criminal al Redactor de "El Católico" y dice: "el Señor Obispo me ha ofrecido dinero para que me desdiga y lo he rechazado con el desprecio que merece, me atemorizó y amenazó con el infierno y me puse á reir". ${ }^{70}$

Por su parte, El Católico se declaró incapaz "de falsificar una firma" y reiteró que el original a la carta de Quiñónez se encontraba en su Redacción, "a disposición de cuantos quieran examinar su 


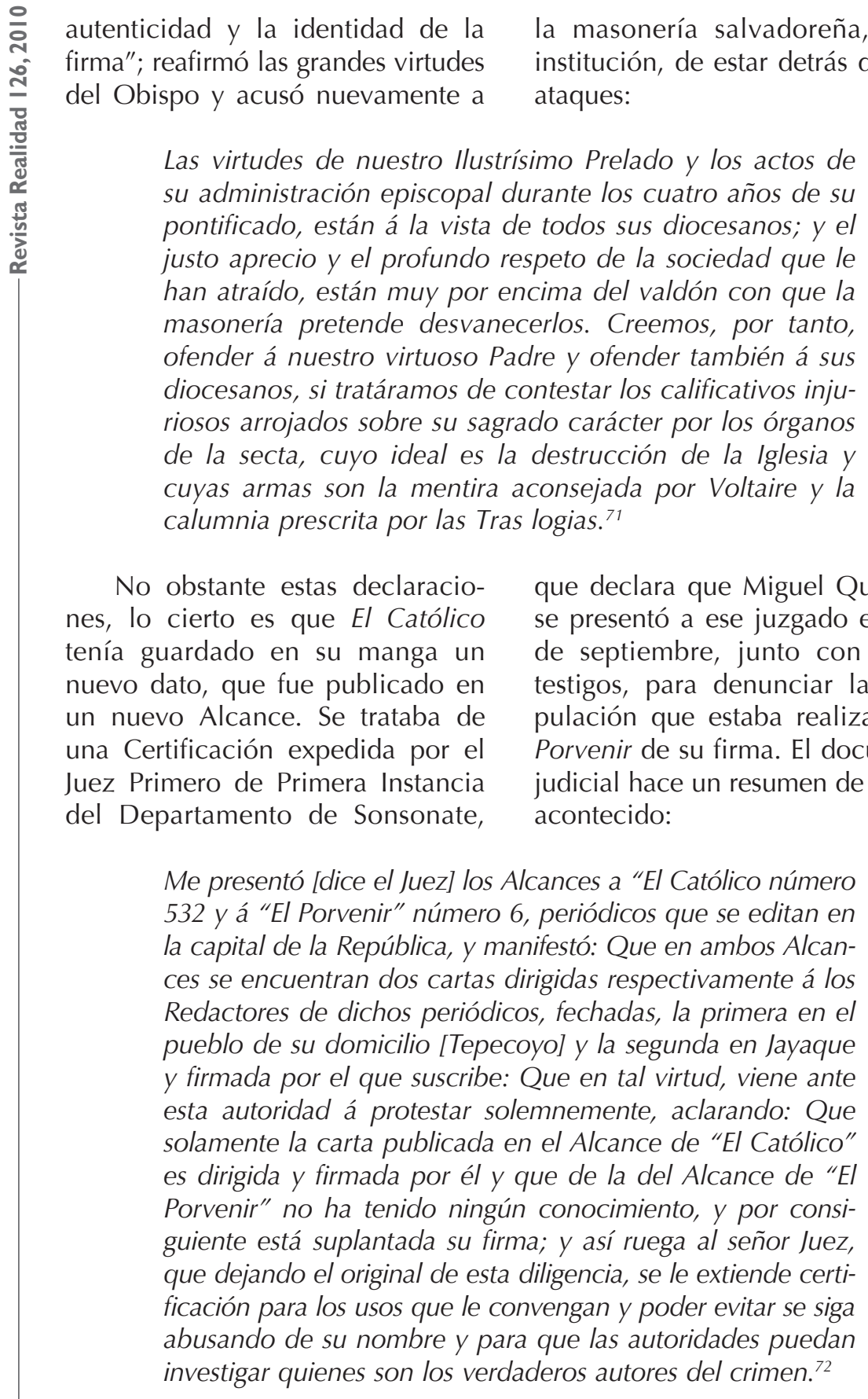


El Católico concluyó sus comentarios a la publicación de este nuevo documento judicial, lanzando a El Porvenir el reto de presentar "otro documento público de igual naturaleza y con el testimonio de otros cuatro testi- gos tan honorables y fidedignos, como los firmantes de la protesta y aclaración", al tiempo que no desaprovechó la oportunidad para volver atacar a los masones, y en este caso más específicamente a la Logia "Excelsior N 17":

"El Católico" prescinde de más comentarios, y somete esta cuestión al juicio y al fallo de la sociedad. "El Porvenir" y "El Católico", ó mejor dicho, el representante de los masones de la Logia Excelsior, y el representante de los católicos de la Diócesis, están frente á frente ante la opinión pública. Ella decidirá quién procede con la razón y la justicia; quién, con la mentira y la calumnia; quién respeta la sociedad, y quién se burla de ella y la engaña. ${ }^{73}$

Sin embargo, al parecer El Porvenir no tenía interés en demostrar judicialmente la autenticidad de la firma de Quiñónez que calzaba la carta que había publicado, tal como lo exigía El Católico, sino enviar por correo a otros medios la Carta para que fuera publicada. En el correo se adjuntaba la siguiente nota de Protesta, también supuestamente firmada por Quiñónez:

En nombre mío, de mi familia y de la rectitud de todas las conciencias honradas, protesto ante Centro-América y ante el mundo entero, contra la suplantación de mi nombre y la falsificación de mi firma hechas en "El Católico", de San Salvador, con ofensa de mi dignidad, de mis conveniencias pecuniarias y de mis profundas convicciones. Ni amenazas ridículas, ni ofertas corruptoras quebrantarán jamás la certeza de mi caracter.- Miguel Quiñones. ${ }^{74}$

Por supuesto que la Carta y la Nota de Protesta no eran enviadas en nombre de El Porvenir, sino de Quiñónez, teniendo que recurrir para ello una vez más a la falsificación de su firma. Hasta donde he podido determinar, fue enviada al periódico semi-oficial, El ECO Nacional, de San Salvador, y La América
Central, que se publicaba en Santa Ana. Dada la intensa disputa que mantenían El Católico y El Porvenir sobre el asunto, los redactores de $E I$ Eco Nacional decidiera no publicar la Nota y la Carta de Quiñónez hasta que no diera pruebas fidedignas de que se trataba de su firma; ${ }^{75} \sin$ embargo, el diario de Santa Ana 
sí lo hizo, según aclaró después El Católico. ${ }^{76}$ Esto llevó a Federico Prado, Agente General de El Católico, a enviar el 6 de Septiembre a la Redacción de La América Central una copia de la Certificación del Juzgado de Sonsonate. ${ }^{77}$

Sin embargo, esto no quiere decir que El Eco Nacional se identificara totalmente con los planteamientos de El Católico, pero tampoco lo hacía con la postura defendida por El Porvenir. De hecho publicó una breve nota en la que descalifica el conflicto periodístico que a estas alturas parecía nunca terminar, y - a juicio de $E I$ Eco Nacional- no hacía más desprestigiar la alta labor a que estaba Ilamada a desempeñar la prensa en el país:

Está "El por llegar" encarnizado contra el colega católico, lanzándose injurias á diestra y siniestra, sin ton ni son. Lastimoso es creer que la prensa se rebaje y descienda hasta un terreno indigno de su misión. Las grandes cuestiones se resuelven por medio de grandes ideas y no por medio de insultos y chocarrerías. No transijimos con el uso que se pretende hacer de la libertad de prensa". ${ }^{78}$

Por supuesto, El Católico respondió ampliamente a este reclamo de El ECo Nacional, y como era de esperarse justificó su actuación en la virulencia con que El Porvenir había utilizado la libertad de prensa para atacar irresponsablemente al clero salvadoreño. En otros textos publicados por El ECO Nacional, y reproducidos por El Católico, da la impresión de que la postura de los redactores de El ECo Nacional era mucho más agresiva para El Porvenir. ${ }^{79}$
Para terminar, digamos que Quiñónez decidió apersonarse el 13 de Septiembre al Tribunal de Primera Instancia de Nueva San Salvador (Santa Tecla) a presentar una nueva queja por el uso abusivo que se estaba haciendo de su firma. En su declaración, reproducida por El Católico, repitió lo expuesto ante el Tribunal de Sonsonate, y añadió los siguientes elementos:

... $2^{\circ}$ que nunca ha dirigido á los Redactores de "El Porvenir" ninguna carta por medio de la administración de correos de Sonsonate ni de la de Santa Tecla, y por tanto son supuestas las que se le atribuyen y falsificada su firma: $3^{\circ}$ que tampoco ha dirigido al Redactor de la "América Central" de Santa Ana, ninguna protesta y en consecuencia es igualmente falsificada y suplantada su firma en la publicada por aquel periódico: $4^{\circ}$ que tampoco ha dirigido 
ningún remitido á los Redactores de "El ECo Nacional", y que por tal razón el que éstos recibieron con la forma del exponente y no creyeron conveniente publicar, es de igual manera suplantado y falsificado. ${ }^{80}$

e. Acusaciones al Padre Funes y orden de captura fallida en contra del Redactor de El Porvenir

El Porvenir también publicó en el número 4, correspondiente al 15 de Julio, un artículo titulado "El Católico" y firmado por "Fray Trancaso" en el que -al parecer- lanzó otras acusaciones en contra del Padre José Miguel Funes. ${ }^{81}$ Lamentablemente, El Católico nunca llegó a afirmar con claridad cuál era el contenido de tales acusaciones; solo señaló que después de ser "vilmente calumniado", Funes inició una acción judicial ante el Juzgado Segundo de Primera Instancia de San Salvador, "contra el calumniante, para vindicar su carácter sagrado ante la sociedad" ${ }^{82}$

$\mathrm{Y}$ en efecto, el 30 de agosto compareció ante el referido Juzgado el "Editor Responsable de 'El Porvenir'", que como ya se ha adelantado, se trataba de Silverio Angulo Guridi. De acuerdo con El Católico, Angulo Guridi "no negó el escrito calumniante, pero tuvo el valor de afirmar que no se refería al Padre don José Miguel Fúnes de San Salvador, sino á otro sacerdote del mismo nombre pero de otra diócesis" ${ }^{83}$ Más en concreto, de acuerdo con una Certificación judicial extendida por el Tribunal donde se ventilaba el caso, y publicada posteriormente por El Católico, Angulo Guaridi declaró lo siguiente: "soy yo el autor del referido artículo; pero con lo dicho en él, no he tenido la intención de injuriar al Presbítero don José Miguel Funes, á quien siempre he tenido por un virtuoso sacerdote: que en el mencionado artículo, no me refería al padre José Miguel Funes de esta República, sino al padre Funes de la República de Honduras". ${ }^{84}$

No obstante la excusa, de acuerdo con El Católico, el Juez "que no es de los que se dejan engañar con tales arterías, proveyó el auto de prisión contra el señor Guridi y lo mandó capturar por uno de los policías de la Municipalidad". ${ }^{85}$ Esta orden de captura se decretó el 3 de Septiembre, según la Certificación judicial, pues se determinó que "no habiendo en esta [Diócesis] Sacerdote que lleve este apellido, sino el presbítero Don José Miguel Funes, y estando comprendida la imputación que se le hace en el número 2 del art $^{\circ} 413$. Pn, declárase abusivo el artículo que lleva por título 'El Católico', firmado 'Fray Trancaso'" ${ }^{\prime}{ }^{86}$ En consecuencia, y "habiendo mérito suficiente para la detención de Silverio Angulo Guridi 
Lewis", el Tribunal libró "las órdenes de captura correspondiente" el 10 de Septiembre. ${ }^{87}$

Sin embargo, el día que se ejecutó la orden, de acuerdo con El Católico, Angulo Guridi convenció al agente policíal que lo custodiaba de que "en lugar de llevarlo á la cárcel, lo llevase á la Dirección de policía"; y, entonces, para sorpresa y escándalo de El Católico, "el señor Director [de la Policía], si saber nosotros las razones de su extraño proceder, en lugar de enviarlo á la autoridad respectiva, lo puso en libertad". ${ }^{88}$ Esta denuncia sobre la irregularidad en el proceso de detención de Angulo Guridi que involucraban directamente al Director de la Policía, provocaron una respuesta del periódico semioficial, El ECo Nacional. Éste calificó de "queja infundada de 'El Católico' contra el Director General de la Policía", ${ }^{89}$ y sostuvo que el semanario ultramontano desconocía las razones por las cuales el Director de la Policía había actuado de esa manera. Por su parte, El Católico respondió que "no tuvo intención de quejarse ó de formular un cargo; sino de limitarse á referir simplemente los hechos", y añade que "Ilamó extraño el proceder [del Director Ruiz], porque no sucede así ordinariamente, porque en lo exterior tiene la apariencia de favorecer al culpable y por sus efectos, dificulta la secuela del juicio". ${ }^{90}$ En cualquier caso, El Eco Nacional aclaró que Ruiz no detuvo a Angulo Guridi porque el agente de la policía municipal que lo conducía "no le mostró la orden del Juez"; y por si esa razón -un tanto laxa por cierto- no convencía a El Católico, el medio impreso semi-oficial añadió otra razón para no realizarse la captura, que resulta bastante reveladora, pues sale a relucir el nombre de otro masón, Samuel Dawson, muy probablemente hermano del ya mencionado Guillermo Dawson:

\begin{abstract}
El Coronel Ruíz - escribió El Eco Nacional- lo hubiera detenido en la Dirección aun sin haberse mostrado la orden, bastando para ello que lo hubiese llevado un individuo de la policía municipal; pero al llegar el individuo indicado, se le presentó el señor don Samuel Dawson el cual se comprometió á responder por el señor Guridi, presentándolo al Juez que lo reclamase en cuanto fuese oportuno. ${ }^{91}$
\end{abstract}

Aunque no existe una ficha de Samuel Dawson en el Registro Masónico del Supremo Consejo CentroAmericano, y no puedo determinar con certeza que ya fuera masón en 1892, cuando se desarrolló esta controversia entre El Porvenir y El Católico, Francisco J. Ponte Domínguez ofrece los siguientes datos sobre la biografía masónica de Samuel Cleto Dawson. De acuerdo con Ponte Domínguez, para 1898, 
Dawson era comerciante, ${ }^{92}$ estaba adscrito a Logia "Excélsior $\mathrm{N}^{\circ} 4^{4}$ (antes "Excélsior $N^{\circ} 17$ ) de San Salvador, donde desempeñaba el cargo de Secretario; ${ }^{93}$ para Marzo de ese año ostentaba el Grado $30,{ }^{94}$ pero para el 24 de Abril se le había otorgado el Grado 32; ${ }^{95}$ era además "Gran Elegido Caballero Kadosh"96 y miembro del "Sobe- rano Capítulo Rosa Cruz Ricardo Corazón de León $\mathrm{N}^{\circ} 2^{\prime \prime}$, en el que desempeñaba el cargo de Maestro de Ceremonias. ${ }^{97}$ En cualquier caso, es muy probable que El Católico supiera de la condición masónica de Samuel Dawson, si tomamos en cuenta que su nombre y el de Guillermo Dawson son asociados a los de Rafael Reyes:

Para que las palabras se toman como de quien vienen, es necesario que se diga el nombre y cualidades de los que las profieren. Por eso "El Católico" ha mentado el nombre del H.: Dr. Don Rafael Reyes, y lo ha señalado como corruptor de la enseñanza oficial, y el sectario impugnador del catolicismo. Por eso últimamente ha mentado el nombre de los señores Dawson, cuyas ideas y carácter están ya conocidos en su periódico obsceno "El Fiscal"..$^{98}$

\section{Conclusiones: del antimasonismo "católico-periodístico" a las amenazas de agresiones violentas de un "católico de corazón"}

Quisiera concluir este trabajo examinando brevemente un ejemplo concreto de cómo, a raíz del debate que hemos examinado con detenimiento, el antimasonismo "católico-periodístico" se fue tornando cada vez más violento y fue dando paso a un tipo de antimasonismo que estaba dispuesto a pasar de la lucha periodística a las agresiones violentas, violencia que en ningún momento se desvinculó o se trató de desvincular del catolicismo. Me refiero al texto titulado "Impresiones y opiniones", firmado por "Un Católico de Corazón" y publicado en la primera plana de la edición del 11 de septiembre de $E I$ Católico. ${ }^{99}$

El autor señala que el texto lo escribió en respuesta a "las hostilidades masónicas de "El Porvenir" á nuestra santa Iglesia y á sus sagrados ministros". ${ }^{100}$ Por su parte, El Católico dejó muy en claro que se trataba de un "Remitido", y por tanto que no representaba la postura oficial del semanario; sin embargo resulta del todo lógico pensar que los Redactores simpatizaban con los contenidos del mismo, desde el 
momento que se decidió no solo por publicarlo, sino también de hacerlo nada menos que en la primera página de su edición.

Yendo al contenido del mismo, el texto está dividido en tres partes. En la primera de ellas, el autor describe las "Impresiones" que ha causado entre los católicos los artículos publicados por El Porvenir; en la segunda parte, desarrolla las "Opiniones" que ha generado el extraño silencio que mantuvo el Obispo de San Salvador a lo largo del debate; y en la tercera, expone las razones por las cuales solicita a la redacción de El Católico su nombre sea omitido, si es que se publicaba el texto, como de hecho se hizo. Voy a resumir brevemente el contenido de cada uno de estas partes, comenzando por las "Impresiones".

El autor del texto, es decir, nuestro "Católico de corazón", señala que tuvo la oportunidad de conversar con tres clases de católicos sobre esta disputa periodística, y los clasifica de la siguiente manera: los "débiles", los "pusilánimes" y los "ardientes". Se trata de una categorización interesante que nos revela el impacto que había tenido las publicaciones de El Porvenir sobre el pueblo católico. De acuerdo con el texto, los "católicos débiles se escandalizan y se admiran de que doctrinas tan verdaderas y leyes tan santas como las de nuestra santa religión, sean atacadas con tanta acrimonia y con tanto des- precio" por El Porvenir; en cambio, los católicos "pusilánimes temen la publicación de esos ataques, porque según ellos, pueden hacer perder la fe á muchos católicos y convertirlos en masones ó en librepensadores"; finalmente, los "católicos ardientes se indignan contra los que así insultan, calumnian y ridiculizan nuestras creencias y nuestros sagrados ministros". ${ }^{101}$

Nuestro "Católico de corazón" reconoció que no se identificaba con ninguno de los tres grupos descritos, pues consideraba que "tales ataques me confirman más en mi fé", y sentó una tesis que repetirá en más de una ocasión a lo largo del texto: los ataques constituían "un bien providencial para la Iglesia del Salvador y me compadezco de sus autores". En otros términos, su fe, al final de cuentas, quedaba fortalecida, y todo este debate le confirmaba que la Iglesia católica "es la única verdadera y es la única fundada por Cristo", y por otro, que "la masonería y el librepensamiento son el error y el vicio"; por lo que también, lejos "de temer que 'El Porvenir' haga perder la fe á algunos católicos y los convierta en masones y libre-pensadores, creo al contrario, que sus ataques son un bien providencial á nuestra diócesis"; y aquí tuvo que admitir que "en nuestra diócesis hay mucho de sopor, mucho de indiferentismo religioso; y tal vez la divina Providencia haga en ella con los ataques de "El Porvenir" lo mismo 
que ha hecho siempre y en otras partes, esto es, que el espíritu de los católicos se reanime y despierte á las voces de sus enemigos"; pero muy lejos de su pensamiento dejar de considerar a los redactores de El Porvenir como "enemigos"; y en tanto que creyente, nuestro "Católico de corazón" estaba claro sobre cuál era el patrón de conducta a seguir ante una situación de ataque como la que estaba viviendo la Iglesia: "Nosotros, si queremos imi- tarle [a Jesucristo], aborrezcamos y detestemos á la masonería, al librepensamiento, á la impiedad; pero suframos y compadezcamos al masón, al impío, al libre-pensador". ${ }^{102}$

En cuanto a las "opiniones" que se generaban por la conducta que había observado el Obispo, "quien —aclaró- era el más ofendido de todos", nuestro "Católico de corazón" hizo la siguiente clasificación:

Unos opinan que debe hablar; -"por que, dicen, quien calla, otorga". Otros opinan que debe escribir; -por que, dicen, "la prensa, con la prensa". Otros opinan que debe ocurrir, por sí o por un apoderado á los tribunales comunes; - por que esos son, dicen, los defensores de la inocencia y los castigadores de los criminales. Otros en fin opinan, que el Sr. Obispo debe excomulgar al periódico y á los periodistas de "El Porvenir"; - por que, dicen, si no se excomulga á los que profieren tales herejías y así insultan lo más sagrado, ¿para cuando y para quienes la Iglesia reserva su excomunión? ${ }^{103}$

Una vez más, nuestro autor, estuvo en desacuerdo con estas opiniones, pues consideraba que la "conducta que el Ilustrísimo señor Obispo de San Salvador ha seguido y sigue ante las incalificables ofensas y los desesperados ataques á su persona por "El Porvenir", es la más sublime, la más digna y la más conforme á su elevado carácter"; ;04 y desarrolló a continuación con algún detalle estas ideas, pero fueron más de carácter general por lo que no voy a exponerlas aquí. Sólo resta, entonces, aludir a las razones por las cuales nuestro "Católico de corazón" rehusó que su nombre acompañara al texto. Ofreció tres razones, de las cuales me interesa destacar la última, pues es en ella donde se puede apreciar el nivel de violencia que estaba adquiriendo este debate y que seguramente preparó el camino para los niveles de violencia e intolerancia política que van a caracterizar a la llamada "derecha" en El Salvador del siglo XX en su enfrentamiento con un movimiento Comunista mucho mejor organizado:

Finalmente, por que teniendo yo por una parte dos fuertes puños 
y soliendo llevar un listo revólver en mi bolsillo, y por otra careciendo de aquella virtud que hizo célebre al Santo Job y de aquel heroísmo del cristiano que ofrece la mejilla izquierda al que le hiere en la derecha, como lo hace el Ilustrísimo señor Obispo; temo que alguno ó algunos de los Redactores de "El Porvenir" me encuentren derrepente, me digan ó hagan una, y yo les diga ó les haga diez. ${ }^{105}$

No deja de Ilamar la atención -por supuesto dentro de la lógica religiosa de la época- la evidente contradicción que existe entre la certeza con que no duda en calificarse a sí mismo como "Un católico de corazón", y al mismo tiempo su incapacidad de "ofrecer la mejilla izquierda al que le hiere en la derecha" y por ende de hacer diez al que le haga solo una. Es claro que a nuestro buen "Católico de corazón" le parecía aun blandengue la sentencia de Moisés de "Ojo por ojo y diente por diente".

Como ya indicaba, no he podido encontrar registros que nos especifiquen la manera en que concluyó el conflicto entre ambos periódicos, y sobre todo no existen evidencias de que en esta ocasión hayan trascendido a más las amenazas de nuestro "Católico de corazón", pero ciertamente es claro que los niveles de intolerancia en contra de los masones salvadoreños por parte de los católicos en más de alguna ocasión pasaron a más durante el siglo XIX. ${ }^{106}$ Es algo que está todavía por analizarse. Sin embargo, existe evidencia de que en 1882, en Nicaragua, se dio un atentado con armas de fuego en contra del masón español José Leonard quien fuera atacado por promover la masonería en la ciudad de Granada, como lo detalló Enrique Guzmán en su "Diario Íntimo". ${ }^{107}$ A consecuencia de este atentado, Leonard, se vio obligado a emigrar desde Nicaragua hacia El Salvador, durante los años de la Administración de Rafael Zaldívar, quien lo acogió con brazos abiertos y le ofreció importantes puestos en el ramo de la Instrucción Pública. Con todo, repito, he querido con estas reflexiones finales abrir un camino que permita profundizar en las raíces históricas de la intolerancia y la violencia política que caracterizó a El Salvador a lo largo del siglo XX y que fueron Ilevando el debate político y periodístico desde un virulento antimasonismo a un igualmente virulento, pero además- asesino anticomunismo. 
NOTAS

1 Véase Francisco J. Ponte Domínguez, Historia de la masonería en El Salvador, Imprenta "Excélsior", Sonsonate, 1962, pp. 28-29; y Rafael Obregón Loria y George F. A. Bowden, La masonería en Costa Rica: Segundo Período, Trejo Hermanos, Impresores, San José Costa Rica, 1938, pp. 74-78.

2 Cfr. Ítalo López Vallecillos, El periodismo en El Salvador: Bosquejo histórico-documental precedido de apuntes sobre la prensa colonial hispanoamericana, UCA/Editores, San Salvador, 1987.

$3 \quad$ Ibíd., pp. 209-211.

4 "El Porvenir", El Católico [en adelante EC] (522), 12 de Junio de 1892, pp. 5-6. El Católico se publicaba todos los días domingo.

Ibíd., p. 5.

ASCC G33, "Rafael Reyes”, Registro Masónico del Supremo Consejo Centro-Americano N. 886, F. 140. Según la ficha, la Logia Madre de Rafael Reyes fue la "Progreso No 5" de San Salvador, en la que recibió el Grado 1 en junio de 1872. Según la ficha, Reyes recibió, siempre dentro de esta Logia, el Grado 2 el 30 de junio de 1882, y el Grado 3 el 19 de junio de 1882. También se señala que el 5 de Marzo de 1899, Reyes "promueve y funda la [Logia] Progreso \#16. Managua Nicaragua ac y preside su primera S. en instancia”. Finalmente se aclara que el 22 de Marzo de 1899, Reyes "se despide del Tall.: para regresar al Salvador...”

Véase “Acción Judicial”, EC (536), 18 de Septiembre de 1892, p. 7.

“Siempre los mismos", EC (537), 25 de Septiembre de 1892, pp. 7-8.

$9 \quad$ Véase "Certificación judicial”, EC (543), 6 de Noviembre de 1892, pp. 5-6.

10 Véase "El ya viejo é incansable maestro de la juventud salvadoreña", EC (537), 25 de Septiembre de 1892, pp. 6-7.

$11 \quad$ Ibíd., p. 6.

$12 \quad$ Ibíd., p. 7.

13 Ibíd.

14 Véase René Chanta, "Francmasonería, Iglesia y publicaciones impresas en El Salvador: La Discusión, 1881", En Boletín AFEHC N³7, publicado el 04 agosto 2008, disponible en: http://afehc-historia-centroamericana.org/index.php? action $=$ fi aff $\&$ id $=2003$

15 “El Porvenir”, EC (522), 12 de Junio de 1892, p. 5. En el mes de Septiembre, cuando el conflicto con El Porvenir seguía en ascenso, El Católico hizo un nuevo resumen de las críticas que Rafael Reyes había venido desarrollando en sus escritos 


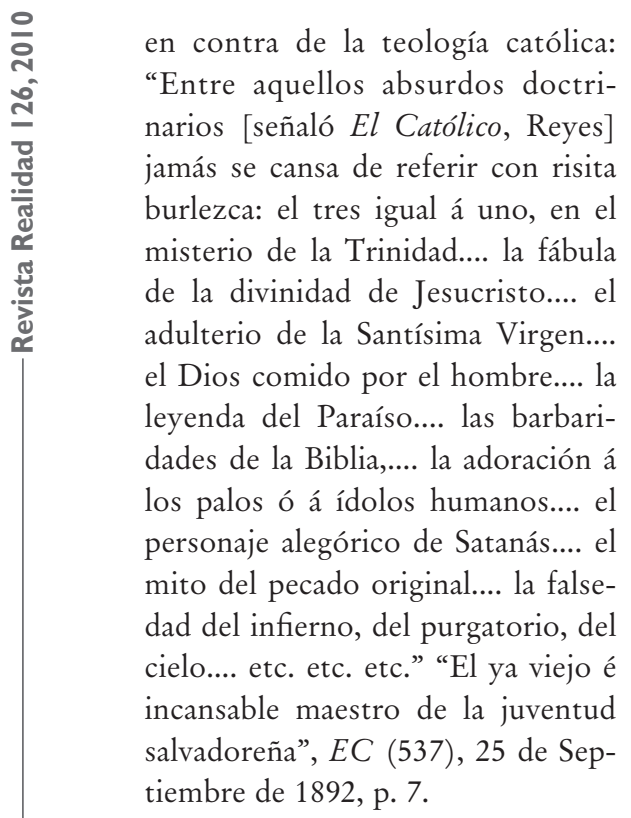

en contra de la teología católica: "Entre aquellos absurdos doctrinarios [señaló El Católico, Reyes] jamás se cansa de referir con risita burlezca: el tres igual á uno, en el merio de la Trinidad.... la fábula adulterio de la Santísima Virgen.... el hombre.... la leyenda del Paraíso.... las barbaridades de la Biblia,... la adoración á los palos ó á ídolos humanos.... el (ne alegórico de Satanás.... el ta falsedad del infierno, del purgatorio, del cielo.... etc. etc. etc." "El ya viejo é salvadoreña”, EC (537), 25 de Septiembre de 1892, p. 7.

“Denuncia y protesta”, EC (518), 8 de Mayo de 1892, p. 5.

“El Porvenir”, EC (522), 12 de Junio de 1892, p. 5.

“Denuncia y protesta”, EC (518), 8 de Mayo de 1892, p. 4. Véase también "Rectificación" y "Remitido", EC (519), 22 de Mayo de 1892, pp. 3-5.

"Denuncia y protesta”, EC (518), 8 de Mayo de 1892, p. 4. Véase además el comentario "La divinidad de Jesucristo", EC (525), 3 de Julio de 1892, p. 4. En él se vuelve a hacer alusión a Reyes y a sus clases en la Universidad.

El País se había fundado no hacia mucho, el 22 de Febrero de 1892,

según detalla López Vallecillos en su El periodismo en El Salvador, pp. 206-207. Su administrador era Matilde Paniagua, que era masón. Aunque no hay una ficha de Matilde Paniagua en el Archivo Masónico del Supremo Consejo con sede en la ciudad de Guatemala, el historiador Francisco J. Ponte Domínguez sostiene en su Historia de la masonería Salvadoreña que, para 1898 , Paniagua era miembro de la Logia "Libertad n 3 ", fecha en la que ya ostentaba el grado 31 (p. 45) y Soberano Príncipe Rosa Cruz (pp. 41-42) y por ende miembro del Soberano Capítulo Rosa Cruz "Ricardo Corazón de León, n 2”, donde para 1898 desempeñaba el cargo de Secretario de esta estructura masónica (p. 36). (3) 3.

28
"Rectificación”, EC (519), 22 de Mayo de 1892, p. 4.

Ibíd., p. 5 .

"Remitido", EC (519), 22 de Mayo de 1892 , p. 5.

Ibíd.

"Nos, Antonio Adolfo Pérez y Aguilar”...”, EC (530), 7 de Agosto de 1892, p. 2.

Ibíd.

"Refutación de la última Pastoral", EC (533), 28 de Agosto de 1892, p.

Ibíd. 
"Protesta del V. Cabildo Eclesiástico", EC (530), 7 de Agosto de 1892, p. 3. Firmaron la protesta, José Antonio Aguilar (Canónigo Dean), Miguel Vecchiotti (Canónigo Tesorero), José Antonio Villacorta (Canónigo Penitenciario) y Marcos Erazo (Canónigo de Gracia y Secretario del Cabildo). Se publicó también dos adhesiones a esta protesta del Cabildo. Véase "Adhesión”, EC (531), 14 de Agosto de 1892, p. 6, firmada por ciudadanos de San Salvador; y "Espontanea Adhesión", $E C$ “Alcance al N ${ }^{\circ} 534$ ", Lunes 5 de Septiembre de 1892, p. 2, firmada por ciudadanos de San Vicente.

"Calumnia”, EC (530), 7 de agosto de 1892, pp. 3-4.

“Otra calumnia”, EC (530), 7 de agosto de 1892, p. 4.

"El M. I. Señor Canónigo Vecchiotti y los redactores de 'El Porvenir', EC (535), 11 de septiembre de 1892, pp. 5-6.

35 "Protesta del V. Cabildo Eclesiástico”, EC (530), 7 de agosto de 1892, pp. 5-6.

36 “Alcance al N ${ }^{\circ}$ 532”, EC, Martes 23 de agosto de 1892, p. 2.
ASCC G33, "Carlos Ezeta”, Registro Masónico del Supremo Consejo Centro-Americano, N 961, F. 215. Según esta ficha, Ezeta tenía treinta años al momento de ser admitido a la masonería, estaba casado, era originario de San Salvador, donde también residía; era militar de profesión y su religión era la católica. Fue miembro de la Logia "Excélsior $\mathrm{N}^{\mathrm{O}}$ 17”, en la que recibió el Grado 1 el 11 de Diciembre de 1885, y el Grado 3, el 5 de Enero de 1887. Sin embargo, se añade que fue expulsado de esta Logia el 31 de Agosto de 1888, es decir dos años antes de llegar a la Presidencia (luego de derrocar a Francisco Menéndez). No obstante lo anterior, es imposible saber por ahora si Ezeta siguió siendo o no masón luego de esta expulsión. 


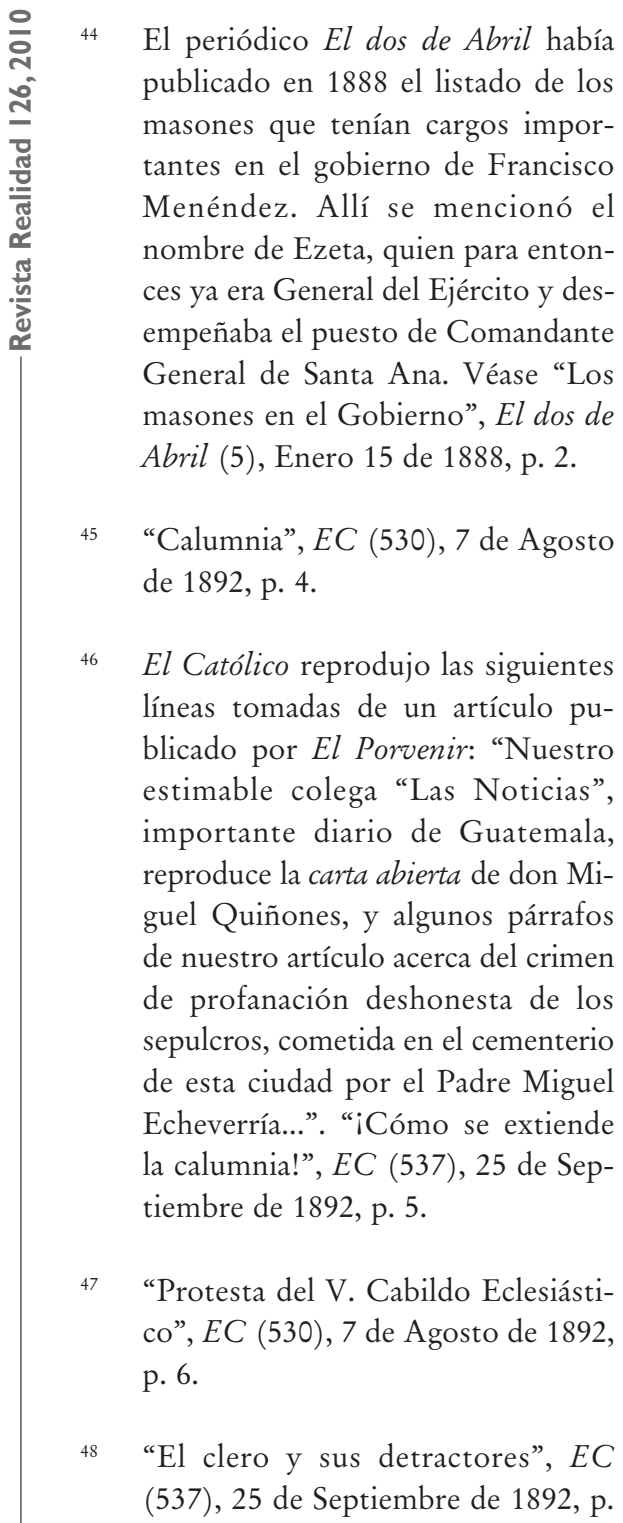
5.

49 Ricardo Roque-Baldovinos, "Periodismo, sensibilidad moderna y nueva autoridad literaria, el caso del periódico La unión (1889-
1890), El Salvador”, Boletín AFE$H C \mathrm{~N}^{\circ} 37$, publicado el 04 agosto 2008. Disponible en: http://afehchistoria-centroamericana.org/index. php? action $=$ fi_aff\&id $=1978$

50 "Protesta del V. Cabildo Eclesiástico”, EC (530), 7 de Agosto de 1892, p. 6 .

51 “Otra calumnia”, EC (530), 7 de Agosto de 1892, p. 4.

52 "El M. I. Señor Canónigo Vecchiotti y los redactores de 'El Porvenir'”, EC (535), 11 de Septiembre de 1892, pp. 5-6. Cursiva en el original.

53 Ibíd.

54 "Protesta del V. Cabildo Eclesiástico”, EC (530), 7 de Agosto de 1892, p. 6.

55 En el mes de septiembre, El Católico publicó una carta de Benito Marroquín, hermano del difunto Padre Vicente Marroquín, en la que desmiente todo lo referido por $E l$ Porvenir. Véase "Carta importantísima”, EC (536), 18 de Septiembre de 1892, p. 6.

56 "Protesta del V. Cabildo Eclesiástico”, EC (530), 7 de Agosto de 1892, p. 5 .

57 “Alcance al N ${ }^{\circ} 532 ”, E C$, Martes 23 de Agosto de 1892.

58 “Reproducción”, EC (533), 28 de Agosto de 1892, p. 3. 
“Alcance al N ${ }^{\circ}$ 532”, EC, Martes 23 de Agosto de 1892, p. 1.

Ibíd.

Ibíd.

ASCC G33, "Guillermo Dawson", Registro Masónico del Supremo Consejo Centro-Americano, $\mathrm{N}^{\circ} 969$, F. 223. De acuerdo con esta Ficha, Dawson tenía 34 años al momento de elaborarse, y dado que fue admitido en 1887, es muy probable que su año de nacimiento haya sido en 1853. Se añade que Dawson era salvadoreño, estaba casado y residía en San Salvador, su ocupación era “tenedor de libros” y su religión era la católica.

"El dos de Abril", El dos de Abril (17), 26 de febrero de 1888, p. 1.

“Dirección General de Rentas”, Diario Oficial (2), sábado 2 de enero de 1892, p. 6.

"Personal docente y administrativo del Instituto Nacional, durante el año de 1891”, Diario Oficial (20), Sábado 23 de enero de 1892, p. 85.

"Una explicación a 'El Eco Nacional', EC (535), 11 de septiembre de 1892, p. 4.

Ibíd., p. 2.

Ibíd. a Quiñónez rezaba de la siguiente manera: "Señor don Miguel Quiñónez.- Hemos recibido un remitido autorizado con su nombre. Como los conceptos que en él expresa son graves para un periódico de esta capital, y como no conocemos su firma, le advertimos por el presente que no le daremos publicidad en tanto nos remita su firma autenticada por el alcalde de la población en donde usted se encuentra.- LL. RR.”. "Laudable prudencia”, EC (535), 11 de Septiembre de 1892, p. 5

Véase al respecto del comportamiento de El Eco Nacional las siguientes notas publicadas por El Católico: "Laudable prudencia” y "Gracias", EC (535), 11 de Septiembre de 1892, pp. 5 y 6 . de septiembre de 1892, pp. 5-6. 


\begin{tabular}{|c|c|c|c|}
\hline 78 & "Una explicación a 'El Eco Nacio- & 91 & Ibíd. \\
\hline \multirow{4}{*}{79} & 1892, p. 3. & 92 & Francisco J. Ponte Domínguez, \\
\hline & $\begin{array}{l}\text { Véase, "El Porvenir negro", EC } \\
\text { (535), } 11 \text { de septiembre de } 1892,\end{array}$ & & $\tilde{n} a^{\prime}$, p. 37. \\
\hline & p. 6; "Literatura pornográfica", EC & 93 & Ibíd., p. 41. \\
\hline & 8. & 94 & Ibíd., pp. 41 y 96. \\
\hline \multirow[t]{2}{*}{80} & "El Señor don Miguel Quiñónez”, & 95 & Ibíd., p. 45. \\
\hline & $\begin{array}{l}E C(536), 18 \text { de septiembre de } 1892, \\
\text { p. } 7 .\end{array}$ & 96 & Ibíd., p. 41. \\
\hline \multirow[t]{2}{*}{81} & Véase “Acción Judicial”, EC (536), & 97 & Ibíd., p. 36. \\
\hline & $\begin{array}{l}18 \text { de septiembre de } 1892, \text { p. } 7, \text { y } \\
\text { "Certificación judicial" EC (543), } 6 \\
\text { de Noviembre de } 1892, \text { p. } 7 .\end{array}$ & 98 & $\begin{array}{l}\text { "Una explicación a 'El Eco Nacio- } \\
\text { nal”, EC (535), } 11 \text { de septiembre de } \\
1892, \text { p. } 4 .\end{array}$ \\
\hline 82 & $\begin{array}{l}\text { "Acción Judicial”, EC (536), } 18 \text { de } \\
\text { septiembre de 1892, p. } 7\end{array}$ & 99 & $\begin{array}{l}\text { "Impresiones y opiniones", EC } \\
\text { (535), } 11 \text { de septiembre de } 1892, \mathrm{pp} .\end{array}$ \\
\hline 83 & Ibid. & & $1-3$. \\
\hline \multirow[t]{2}{*}{84} & $\begin{array}{l}\text { "Certificación judicial" EC (543), } 6 \\
\text { de noviembre de } 1892, \text { p. } 7 \text {. }\end{array}$ & 100 & Ibíd., p. 1. \\
\hline & & 101 & Ibíd. \\
\hline 85 & $\begin{array}{l}\text { “Acción Judicial”, EC (536), } 18 \text { de } \\
\text { septiembre de } 1892, \text { p. } 7 .\end{array}$ & 102 & Ibíd. \\
\hline \multirow[t]{2}{*}{86} & "Certificación judicial" EC (543), 6 & 103 & Ibíd., p. 2. Cursivas en el original. \\
\hline & & 104 & Ibíd. \\
\hline \multirow[t]{2}{*}{87} & Ibíd. & & \\
\hline & & 105 & Ibíd., p. 3. \\
\hline 88 & $\begin{array}{l}\text { “Acción Judicial”, EC (536), } 18 \text { de } \\
\text { septiembre de 1892, p. } 7 .\end{array}$ & 106 & $\begin{array}{l}\text { Véase, por ejemplo, los choques } \\
\text { entre partidarios del ultramontanis- }\end{array}$ \\
\hline 89 & $\begin{array}{l}\text { "Rectificación", EC (537), } 25 \text { de } \\
\text { septiembre de } 1892, \text { p. } 8 .\end{array}$ & & $\begin{array}{l}\text { mo y del liberalismo masónico que } \\
\text { se registraron durante las elecciones } \\
\text { para Asamblea Constituyente rea- }\end{array}$ \\
\hline 90 & Ibíd. & & lizadas en agosto de 1885: "Al pú- \\
\hline
\end{tabular}


blico", La República (159), viernes 28 de agosto de 1885, pág. 2; "Las elecciones", La República (161), lunes 31 de agosto de 1885, pág. 2; "La Voz de Centro-América”, EC (218), domingo 23 de agosto de 1885, págs. 664- 665; "Armas de mala ley", $E C$ (220), domingo 6 de septiembre de 1885, pág. 679 .

Véase las siguientes entradas del "Diario Íntimo" de Enrique Guz- mán correspondientes a 1881: 5 y 9 de febrero, 25 de abril; 29 de mayo; 26 de agosto; 2 de septiembre; 10 de octubre. Para 1882, las siguientes entradas: 5 de enero; 6 de febrero; 7 y 9 de mayo; 23, 29 y 31 de octubre; 8 de diciembre. Para 1883, 13 y 27 de marzo; 26 de abril; 6 de mayo. Todas ellas figuran en Revista Conservadora (7), febrero de 1961 y (8), marzo-mayo de 1961. 